Australian Hotels Association, representing licensed premises and some restaurants. Information from Healthy Buildings International, an organisation with strong ties to the tobacco industry, ${ }^{2}$ was much in evidence.

When the ACT Government proposed its legislation, it did so in the belief that it was only a matter of time before other jurisdictions would adopt a legislative basis for smoke-free public places. Whether, when, and how this happens will depend on the success of the Australian public health community in presenting the issues in a way that is informative and persuasive to the media, the public, and elected representatives.

Department of Health MARG GOODIN Australian Capital Territory Canberra ACT 2601 Australia

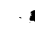

$=$

1 McAllister I. Public opinion in Australia on restricting smoking in public places. Tobacco Control 1995; 4: 30-5.

2 Levin M. Who's behind the building doctor? Secondhand smoke. The Nation 1993 (August 9); 257(5): 168.

$-$

$=$

\section{Adolescent use of cigarette vending} machines

To the Editor-Public health officials have focused attention on the nature and extent of youth access to tobacco products in the United States. ${ }^{1}$ Studies have clearly shown that minors can purchase cigarettes unfettered. ${ }^{2}$ While model legislation calls for comprehensive measures to thwart youth access to tobacco, ${ }^{3}$ many communities have initially focused on regulating cigarette vending machines.

Tobacco control advocates, as well as the tobacco industry and retailers, recognise that a small percentage of youth tobacco sales is through vending machines. However, vending machines should be cause for concern because of their ubiquitous nature.

A highly publicised mall intercept survey commissioned by the National Automatic Merchandising Association (NAMA) found that teenagers (13-17 years old) generally used over-the-counter sources for purchasing cigarettes. Upon closer reading of the NAMA results, one sees that the younger the youth, the more likely will they be to use a cigarette vending machine. The survey showed that 13 year old smokers were 11 times more likely to use a vending machine than 17 year olds.

In the spring of 1993 , more than 60000 students in grades seven, nine, and 12 (12-18 years old) participated in the Pennsylvania tobacco survey for students, which was conducted for the Pennsylvania Department of Health. ${ }^{5}$ Using a 121 item self-completed questionnaire, administered in a classroom setting, this research aimed to collect baseline data about youth behaviour patterns and attitudes about cigarettes and smokeless tobacco. These students came from a stratified random sample of 371 public and non-public schools. Care was given to the proportional representation of the geographic, ethnic, gender, economic, and grade composition of the state. A total of 60778 students was surveyed, including a random sample of 55563 students and an oversampling of 5215 students in various target areas. After excluding the oversampled respondents and unusable questionnaires, the population on which our results are based is $\mathbf{5 4 7 4 1}$ students.

Our study confirms the finding that the younger the adolescent, the more likely that they will use a cigarette vending machine rather than over-the-counter sources (that is, convenience stores, gas stations, supermarkets, or pharmacies). Seventh graders (12 to 13 year olds) were 2.2 times more likely to "perceive" vending machines as the easiest place to buy cigarettes than ninth graders (95\% confidence interval $[\mathrm{CI}]=2.1$ to 2.3 ). Seventh graders were 6.6 times more likely to "perceive" vending machines as the easiest place to buy cigarettes than 12th graders (95\% CI $=6.3$ to 7.0 ).

When students were asked on a multiple response question where they actually bought cigarettes, the younger students were more likely to cite vending machines as a source. Seventh graders were 1.5 times more likely to buy cigarettes from a vending machine than ninth graders $(95 \% \mathrm{CI}=1.4$ to 1.7$)$. Seventh graders were 2.6 times more likely to buy cigarettes from a vending machine than 12 th graders (95\% CI $=2.3$ to 2.8 ). A Pearson's $\chi^{2}$ test with one degree of freedom found each of these comparisons to be highly significant ( $\mathrm{p} \ll 0.001$ ).

While the overall volume of cigarette sales to minors from vending machines is much smaller than from over-the-counter sales, the younger, experimental smoker is at greater risk of purchasing from a cigarette vending machine. Tobacco control groups should be aware of this risk to such a vulnerable target audience and should adjust their educational programmes and policies accordingly.

\section{STEPHEN F GAMBESCIA} American Heart Association Southeastern Pennsylvania Affiliate

1 US Department of Health and Human Services. Youth access to cigarettes. New York: US Youth access to cigarettes. New York: US
Department of Health and Human Services, Department of Health and Human Services,
Office of Inspector General, Office of EvalOffice of Inspector General, Office of Eval-
uation and Inspections, 1990. (Publication uation and Inspections,
No OEI-02-90-02310.)

2 Altman DG, Rasenick-Douss L, Foster V, Tye J. Sustained effects of an educational program to reduce tobacco sales to minors. $A m$ Public Health 1991; 81: 891-3.

3 US Department of Health and Human Services. Model Sale of Tobacco Products to Minors Control Act: a model law recommended for adoption by states or localities to prevent the sale of tobacco products to minors. Washington, DC: US Department of

4 Response Research Inc. Findings for the study of teenage cigarette smoking and purchase behavior. For the National Automatic Merchandising Association. Chicago, Illinois: Response Research Inc, 1989.

5 Pennsylvania Department of Health. Tobacco and Pennsylvania's students: the 1993 survey. Harrisburg, PA: Pennsylvania Departmen of Health, 1994.

\section{Son of Premier}

To the Editor - In 1988, the RJ Reynolds Tobacco Company (RJR) introduced a unique cigarette product called Premier. $^{1}$ This product was unique because, unlike conventional cigarettes, Premier heated rather than burned tobacco, thereby significantly reducing tar yields. In October 1988, RJR began test marketing Premier in two
American cities (Phoenix, Arizona, and St Louis, Missouri). However, it did not sell well in these cities and was removed from the market in February 1989

The concept of a smokeless tobacco product, however, did not die with Premier. On 27 November 1994, a New York Times article revealed that $R J R$ was testing a second generation of "smokeless cigarettes" called Eclipse. ${ }^{2}$ Like Premier, Eclipse heats rather than burns tobacco, but is designed somewhat differently. ${ }^{3}$ RJR has been conducting consumer tests of Eclipse in eight different American cities, including Buffalo, New York. $^{2}$

One week after the New York Times story on Eclipse, we undertook an informal mallintercept survey to determine consumer awareness of and interest in trying the "smokeless cigarette". We were curious to see how smokers perceived this product, and were interested to see if non-smokers might be induced to try smoking Eclipse.

Survey respondents were recruited by asking individuals at three shopping malls in Buffalo to participate in a 5 minute interview on cigarette smoking. Overall, interviews were completed with a convenience sample of 94 persons, including 26 smokers, 28 former smokers, and 40 individuals who had never smoked. Only two individuals who were approached to be interviewed refused participation in the survey. Because we were not sure to what extent persons would know about the Eclipse cigarette, interviewers were given a diagram of Eclipse to show to respondents. To help respondents understand the difference between Eclipse and a conventional cigarette, the diagram also listed several claims made about the product in the New York Times article (that is, reduce tar levels by $90 \%$, eliminate $95 \%$ of secondhand smoke, produce less smoke, contain as much nicotine as a regular cigarette). ${ }^{2}$

Sixty percent of respondents stated that they had heard about the Eclipse cigarette. However, after showing respondents the diagram of Eclipse, it was apparent that most people were unfamiliar with the unique features of the product and how it differed from a conventional cigarette.

None of the never-smokers and former smokers we interviewed expressed interest in trying Eclipse. However, $85 \%$ of the smokers stated that they would be interested in trying the product. Respondents who expressed interest in trying Eclipse were asked to describe benefits they believed to be associated with the product. The most frequently mentioned benefits were less sidestream smoke and tar. All respondents were asked to describe potential problems associated with the Eclipse cigarette. The most often mentioned problems were addiction and disposal of the device.

The vast majority of respondents answered affirmatively to a question about whether Eclipse should be subjected to government testing for safety. However, when asked whether Eclipse should be sold alongside regular cigarettes or by prescription, $70 \%$ said the product should be available like cigarettes. Anecdotal comments received from respondents to our survey give us the impression that both smokers and nonsmokers are sceptical about claims being made about the safety of Eclipse in relation to conventional cigarettes.

A recent study showed that about $70 \%$ of adult smokers in the United States want to stop smoking. ${ }^{4}$ Most of those who do stop smoking do so out of concern for their health. 